\title{
Adjustment determination of kinetic energy and the amount of flow in the area of Spreading, Taking into account the development of inter- amber space
}

\author{
Norkobul Rakhmatov ${ }^{*}$ \\ Tashkent Institute of Irrigation and Agricultural Mechanization Engineers, Tashkent, Uzbekistan
}

\begin{abstract}
At present, major works on the main rivers of Central Asia (Amudarya, Zerafshan, Chirchik, and others) have been carried out and are working to protect the banks from erosion and regulate channels for guaranteed water intake into irrigation channels in areas of great length. For this widely used transverse dam (spur). During the interaction of the dam (spur) with the flow, there is intensive siltation of the inter-amber space. Due to the limited areas for agricultural land in densely populated areas, which usually adjoin the valleys of large rivers, spontaneous and unwarranted development of inter-dammed space on regulated sections of rivers occurs, which may lead to a violation of the design regime of the regulated part of the river. In this regard, the development of methods for the hydraulic calculation of a constrained flow with a partial development of inter-dam space is one of the urgent problems of scientific and practical importance in the design of control structures, their construction, and operation.
\end{abstract}

\section{Introduction}

As it's known, the flow in the river is continuous. An easily mobile medium is characterized by some physical parameters (pressure, velocity, temperature, density, viscosity, etc.). In general, these parameters change from point to point in the stream for one reason or another. Therefore it is necessary to talk about these fields of physical parameters. For a given flux, the fields of physical parameters are interconnected by certain relations that follow from such fundamental laws of nature as the law of conservation of mass, the laws of change of momentum and angular momentum, first and the second law of thermodynamics. Applying these laws to the flow, one can obtain the basic equations that are used to solve problems of motion of such an environment [1-7]. In the general case, the solution of these equations is difficult when the variables are all physical parameters. Therefore, when solving practical problems, they strive to introduce various simplifications. For example, during the flow of a dropping liquid, if it does not heat or cold, the temperature, density, and viscosity can be considered constant at all points of the flow. For such an isothermal uniform flow of an incompressible fluid, only the velocity and pressure fields are considered. The whole fluid flow is often three-dimensional. Representing it

*Corresponding author: rnr08@yandex.com 
consisting of a set of elementary streams, we obtain an inkjet flow model that simplifies problem-solving since the movement in each elementary stream is one-dimensional. The jet stream model is the most common type of fluid and gas flow. Jets are considered to be a flow on both sides of the tangential discontinuity surface. The tangential discontinuity is experienced by the magnitude of the flow velocity, temperature, impurity concentration, etc. The surface of a tangential discontinuity is characterized by the presence of unstable vortices moving along and across the flow, due to which a continuous exchange of masses, i.e., transfer of momentum, heat, etc [8-15].

As a result, a zone of finite thickness with a continuous distribution of velocity, temperature, and impurity concentrations forms at the boundary of two jets: this region is called the zone of intense turbulent mixing. The simplest case of an intensive turbulent mixing zone is formed when a fluid flows out with a uniform distribution of velocities (and across the flow, due to which a continuous exchange of masses takes place between the jets, i.e., the transfer of momentum, heat, etc. As a result, a zone of finite thickness with a continuous distribution of velocity, temperature, and impurity concentrations forms at the boundary of two jets: this region is called the zone of intense turbulent mixing [16-35].

\section{Methods}

The accuracy of the hydraulic parameters of the steam boosts on the shore protection will increase to $25 \%$. This allows you to choose the design of the building protection facility.

The simplest case of an intense turbulent mixing zone is formed when a fluid flows out with a uniform distribution of velocities $\left(\mathrm{U}_{0}=\right.$ const) into a medium moving with a constant velocity $(U=$ const). This simple is that in this case, in the initial section of the jet, the thickness of the intense turbulent mixing is zero. However, the presence of continuous mass exchange through the tangential discontinuity surfaces $\left(0^{!}-2,0 !-1\right)$ 'figure 1 ' leads to an increase in the cross-section of the zone of intense turbulent mixing on the one hand, and on the other, to the disappearance of the weakly perturbed core. The part of the jet within which there is a core is called the initial section.

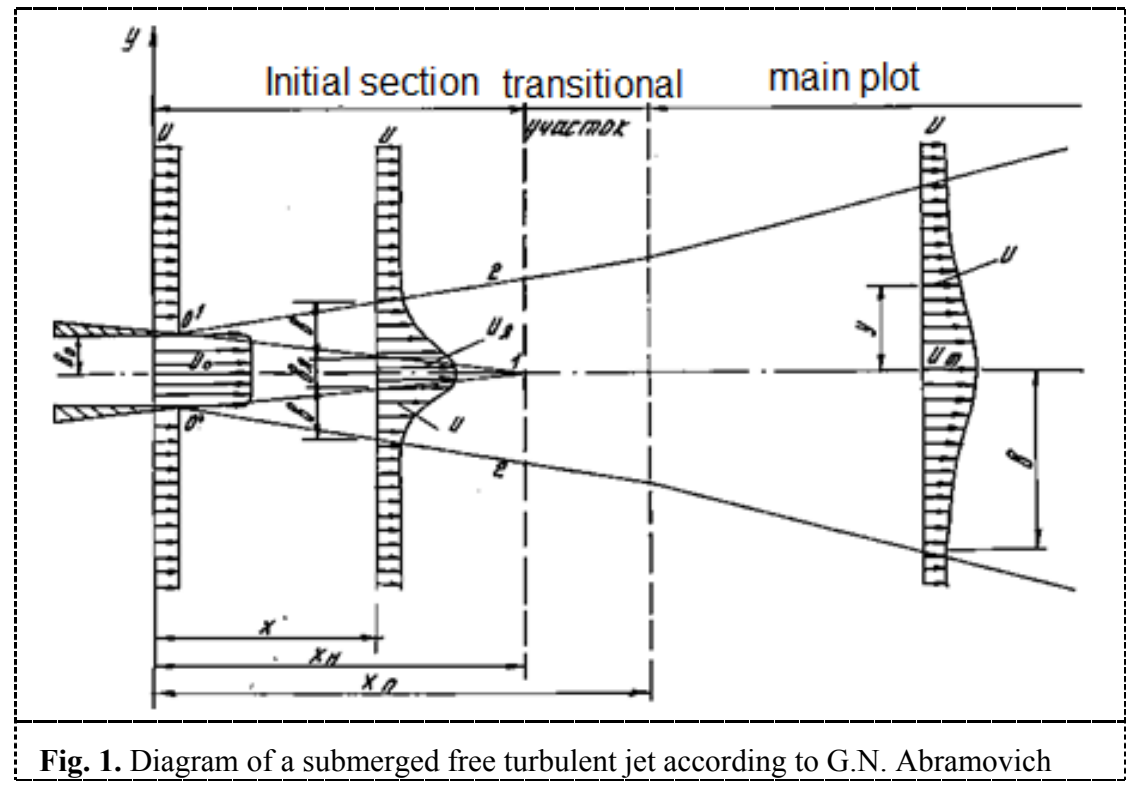


At some distance from the end of the initial section, the jet flow acquires the same form as the flow of liquid from an infinitely small source (in the symmetric case, the source is a point, in the plane - parallel case - a straight line perpendicular to the jet spreading plane). This section of the jet is called the main; between the main and initial parts of the jet is a transition section.

\section{Results and Discussion}

Based on numerous experimental studies with free jets by G. K. Abramovich (1) found that the dimensionless velocity profiles across the width of the zone of intense turbulent mixing are affine and obey the Schlichting theoretical dependence

a) in the initial section $\left(U_{\max }-U\right) /\left(U_{\max }-U_{n}\right)=(1-\eta 1.5) 2$;

$v)$ in the main section $\left(U-U_{n}\right) /\left(U_{\max }-U_{n}\right)=(1-\eta 1.5) 2$;

where: $U, U_{n}$ is average vertical velocity of the flow, respectively, in the zone of displacement and in the zone of reverse currents

$\mathrm{U}_{\max }$ is the maximum average speed on the vertical in the offset zone;

$\eta$-is the relative coordinate of the considered vertical is

$$
\eta=\left(y_{2}-y\right) /\left(y_{2}-y_{1}\right)=\left(y_{2}-y\right) / B
$$

Where: в is boundary layer width; $y_{1}, y_{2}$ are, respectively, the coordinates of the internal and external boundaries of the offset zone; $y$ is coordinates of the point in question

In addition, the author proves that in the presence of a counter-flow, the law of increasing the thickness of the zone of intense turbulent mixing does not depend on the ratio of velocities on the surfaces and increases linearly:

$$
B=c x
$$

Where: $\mathrm{C}$ is constant equal to the initial part $\mathrm{C}=0.27$, on the main $\mathrm{C}=0.22$.

Based on M. A. Mikhalev [8] studies, it was necessary to establish the pattern of change in velocity in the core and the reverse flow region, the law of variation in the core width, and the length of the whirlpool zones.

To solve the problem were used:

a) momentum equations;

b) flow conservation equations;

c) the equation of motion recorded for the transit flow with turbulent shear stresses on the lateral surfaces.

The joint solution of the above equations, with some assumptions, allowed the author to completely solve the tasks.

Research of F.G. Gunko (6) found that the boundary between the transit flow and the whirlpool area has a curvilinear outline, which is determined by the main characteristics of the flow structure. The length of the whirlpool, in this case, is determined from the usual differential equation of non-uniform motion, written for the transit flow: 


$$
\frac{\partial h}{\partial x}=\frac{i-\frac{Q^{2}}{\omega^{2} C^{2} R}\left(1-\frac{\alpha C^{2} R}{g \omega} \cdot \frac{\partial \omega}{\partial x}\right)}{1-\frac{\alpha Q^{2} b}{g \omega^{3}}}
$$

Where: $C, R$ are Chezy coefficient and hydraulic radius of the transit flow with $Q=$ const.

The author did not consider the increased resistance of a separate surface between the transit flow and the whirlpool in solving the problem. According to his method, it is impossible to obtain the distribution of averaged local velocities in the plan. As is known, for a more accurate assessment of possible re-formations of the channel after the dam installation, local speeds play the main role, and knowledge of the magnitude of the average transit flow rate $V_{t}$ is not enough. Levi I.I., Solovyova A.G. $[8,12]$ investigated the flow spreading with a sudden expansion. According to these authors, one of the main factors affecting the length of the whirlpool is shear stress acting on different surfaces. Research of Solovieva A.G. showed that the magnitude of the relationship $\lambda_{V} / \lambda_{D}=10 \div 20$

Where: $\lambda_{\mathrm{V}}$ - the coefficient of hydraulic resistance in the separate surface of the whirlpool; $\lambda_{\mathrm{D}}$ - bottom resistance coefficient.

Levi I.I. [8], is for the two-sided symmetric expansion of the flow, the equation of momentum in the differential form, firstly, for the compartment, including the whirlpool, is formed 'figure 2'. Two equations written in this way with the continuity equation attached to them are solved together and integrated into finite differences, making it possible to find a change in velocity - V, width - in and water levels along the stream. In this case, the friction forces along the bottom, the friction forces on the "coastal" surfaces, and the friction forces on the section surfaces I.I. Levi expresses through the average transit flow rate $-\mathrm{V}$, respectively:

$$
\rho \lambda_{\mathrm{D}} \mathrm{V}_{2} \mathrm{~B} d \mathrm{~s} ; \quad \rho \lambda_{\mathrm{b}} \mathrm{V}_{2} 2 \mathrm{hds} ; \quad \rho \lambda_{\mathrm{V}} \mathrm{V}_{2} 2 \mathrm{~h} d \mathrm{~s}
$$

Where: в is transit width.

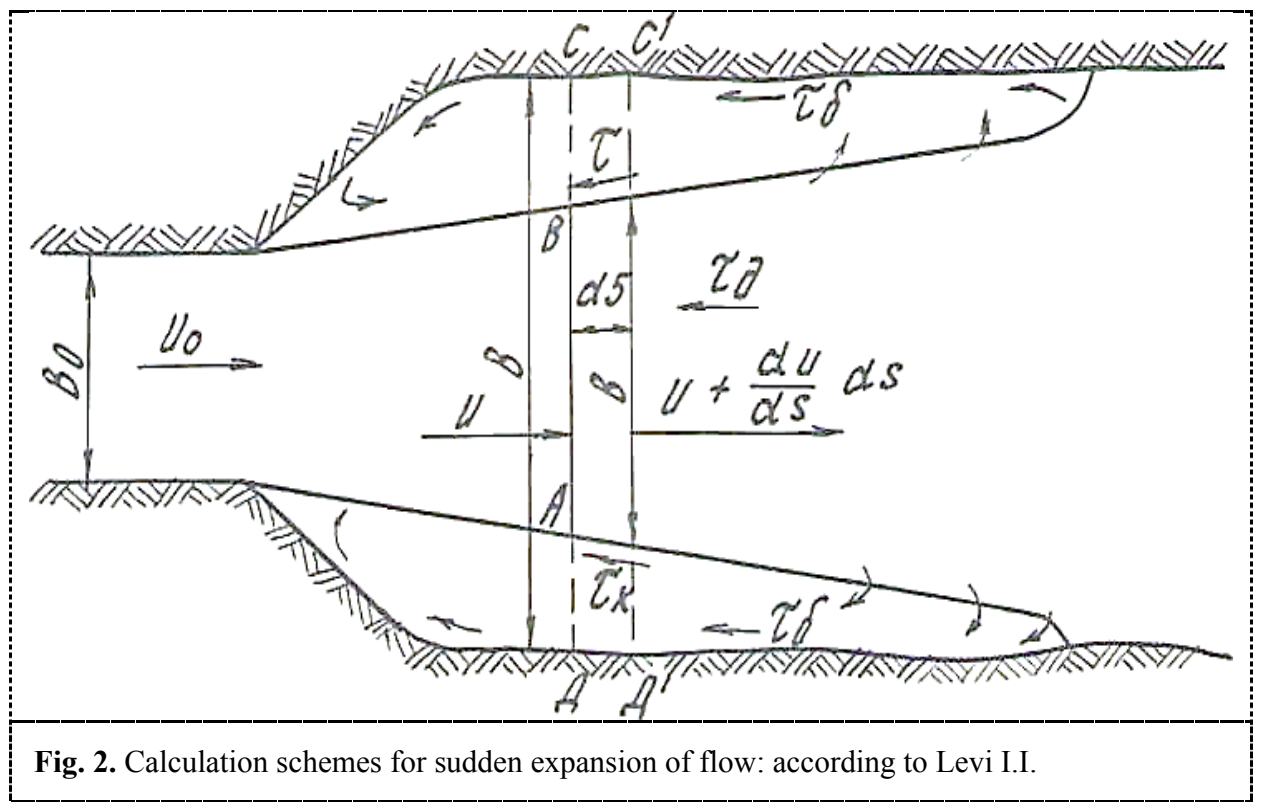


To establish the rule of changes in the parameters of the turbulent flow in the spreading region, we need to know the rule of change in the kinetic energy adjustment $(\alpha)$ and the momentum $\left(\alpha_{0}\right)$. Many researchers in the study of the deformed flow [1-10] took the magnitudes of the kinetic energy adjustments and the amount of motion constant; in fact, the results of experiments conducted in the laboratory of Tashkent Institute of Irrigation and Agricultural Mechanization Engineers showed their variability along the length of the whirlpool.

Since the distribution of velocities over the width of the flow is known, we can determine the nature of changes in $\alpha$ and $\alpha 0$ using the expressions known from the course of hydraulics [11].

$$
\alpha=\frac{\int U^{3} \partial \omega}{V^{3} \omega} ; \quad \alpha_{0}=\frac{\int U^{2} \partial \omega}{V^{2} \omega}
$$

Determining the average transit flow rate from the flow conservation equation and after integrating equation (1), the following dependencies are obtained:

$$
\begin{gathered}
\alpha=\frac{\left(\mathrm{v}_{y}+v\right)^{2}\left[v_{y}+v\left(0.347+0.2 m+0.2 m^{2}\right)+m^{2}\left(B_{1}-v_{y}-1.25 v\right)\right]}{\left[v_{z}+v(0.55+0.45 m)+m\left(B_{1}-v_{y}-v\right)\right]^{3}} \\
\alpha_{2}=\frac{\left(\mathrm{v}_{y}+v\right)\left[v_{y}+v(0.416+0.268 m)+m^{2}\left(B_{1}-v_{y}-0.684 v\right)\right]}{\left[v_{y}+v(0.55+0.45 m)+m\left(B_{1}-s_{y}-v\right)\right]}
\end{gathered}
$$

Using equations (2) and (3), it is possible to calculate the value of adjustments $\alpha$ and $\alpha 0$ in the area of spreading. Experimental studies have shown that due to the pulsation of turbulent flow between the lines 0-2 and 0-3 (Figure 1), the lines 0-3 are extended to $0.2 \mathrm{~lm}$, as shown by N.A. Rakhmanov [9]. The results of the experiments showed that the calculated $\alpha$ and $\alpha 0$ gives a good convergence of the experimental values ranging from the section of maximum constraint (section $\mathrm{C}-\mathrm{C}$ ) to the end of the outer boundary of the turbulent flow (line $0-2$ ); within the $0.2 \mathrm{~lm}$ interval, equation (2) and (3) gives overestimated values. This is explained by the fact that the Schlichting-Abramovich's formula (1) was obtained for free turbulent jets under the assumption

$$
B=B_{c}+c x
$$

In the region of $0.2 \ell \mathrm{m}$, this pattern is violated because the side walls limit the flow. To eliminate this contradiction, the concept of a fictitious width of the turbulent mixing zone was introduced within $0.2 \mathrm{~lm}$. In this case, the dummy width is

$$
B_{f}=B+\Delta B=B+0.2 l_{m} \operatorname{tg} \phi^{0}
$$

where $\varphi^{0}$ is the expansion angle of turbulent flow outer boundary,

which is determined experimentally, for example, for hard (smooth) channels equal to 0.17 radians; $\ell_{\mathrm{m}}$ is the length of the outer boundary of the turbulent mixing zone (Line $0-$ 2). 


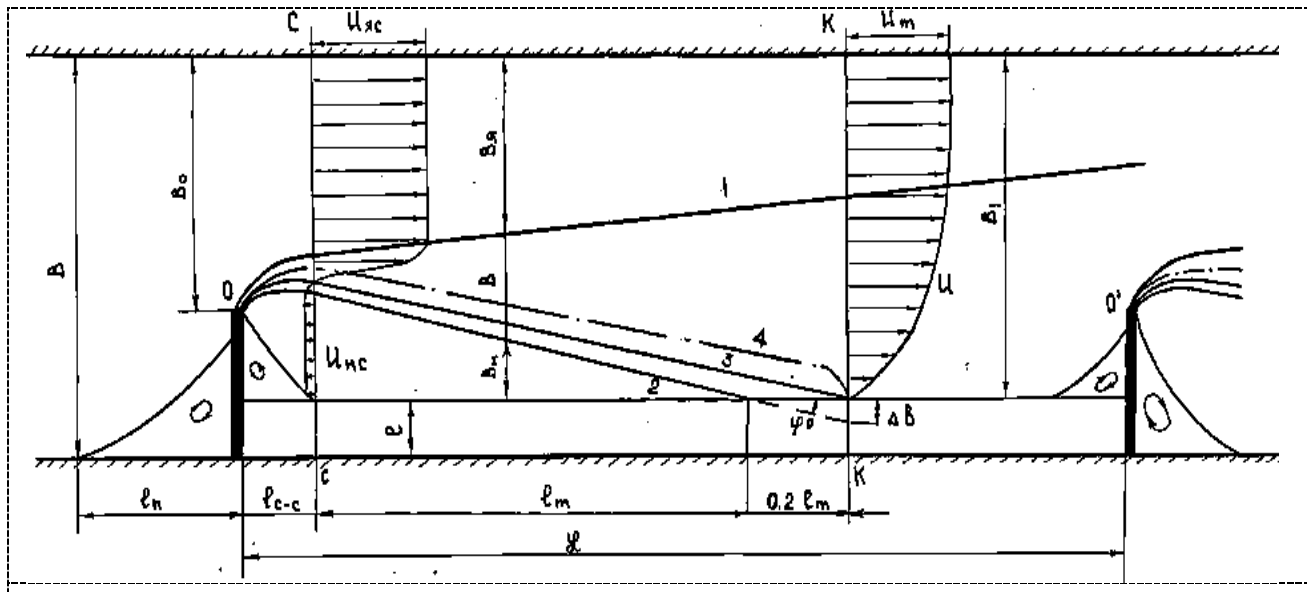

Fig. 3. The design scheme for determining the adjustments of kinetic energy and momentum

The value of $\ell \mathrm{m}$ can be determined by the following dependency:

$$
l_{m}^{*}=\frac{1}{\operatorname{tg} \phi^{0}}\left(\frac{1-k_{0} n}{1-n}-\varepsilon\right)
$$

Considering that within a segment of $0.2 \ell_{\mathrm{m}}$, the speed is $\mathrm{U}_{\mathrm{n}}=0$, and the width of the turbulent mixing zone is $B_{f}$, from (2) and (3) we get:

$$
\begin{gathered}
\alpha=\frac{B^{2}\left(1-k_{0} n\right)^{2}\left[v_{y}+0.347\left(\mathrm{v}+0.2 \ell_{m} \operatorname{tg} \phi^{0}\right)\right]}{\left[v_{y}+0.55\left(\mathrm{v}+0.2 \ell_{m} \operatorname{tg} \phi^{2}\right)\right]^{3}} \\
\alpha_{0}=\frac{B\left(1-k_{0} n\right)\left[v_{y}+0.416\left(v+0.2 \ell_{m} \operatorname{tg} \phi^{0}\right)\right]}{\left[v_{y}+0.55\left(v+0.2 \ell_{m} \operatorname{tg}^{0}\right)\right]^{2}}
\end{gathered}
$$

The results of the experiments showed the adjustment of the theoretical solution; the difference between the theoretical and experimental values of $\alpha$ and $\alpha_{0}$ is $2 \ldots 5 \%$. (Figure 2 ; 3 ). Although the values of the theoretical solution $\alpha$ and $\alpha 0$ have good convergence with the experimental results, by the formula (2), (3), (6), (7), without constructing the velocity field of the flow, it is impossible to use. To establish a real picture of the velocity field, we need to know the value of $\alpha$ and $\alpha_{0}$. To simplify theoretical studies, the value of $\alpha$ and $\alpha_{0}$ is determined by processing the experiment results using the method of regression analysis [7]. As a result of processing, and approximating equation was obtained $(\mathrm{r}=0.95)$.

$$
\alpha=a\left(\frac{1-k_{0} n}{1-n}\right)^{0.365}
$$

Where: a is empirical coefficient, $a=1.07$ for section $C-C, a=1.12$ for section $K-K$ 


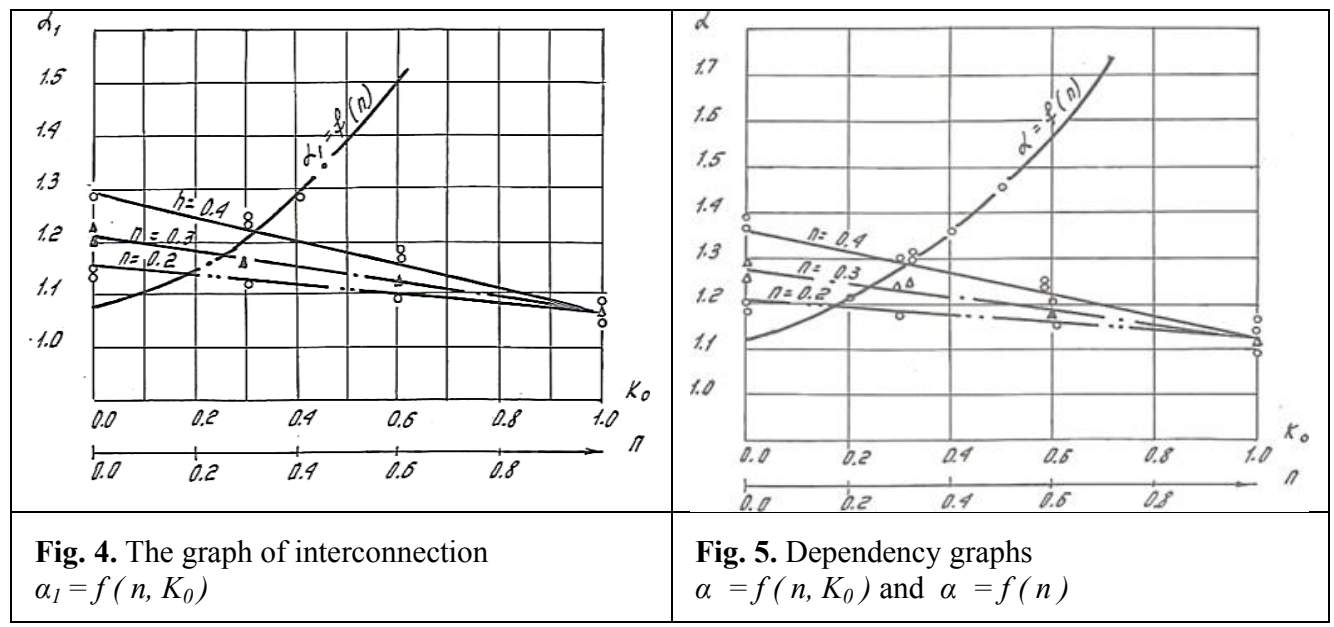

The correlation coefficient is equal to $r=0.96$. There is the following dependence between $\alpha$ and $\alpha_{0}$ by S.T. Altunin [3]

$$
\alpha=3 \cdot \alpha_{0}-2
$$

Having calculated the adjustments of the kinetic energy according to the dependence (9), we determine the adjustments of the momentum by the formula:

$$
\alpha_{0}=\frac{1}{3}(\alpha+2)
$$

Analysis of figure 2 and 3 shows that the values of the adjustments $\alpha$ and $\alpha 0$ depend on the degree of constraint and the development coefficient. From fig. 2 and 3, it can be seen that the value of the adjustments $\alpha$ and $\alpha_{0}$ in the section of maximum compression (section $\mathrm{C}$ C) is obtained more than in other works $[4,5,6,9]$. This is explained by the fact that the backwater created by the second dam influences the uneven distribution of the flow velocity across the canal's width. With an increase in the coefficient of development between the dam space, the influence of the backwater created by the second dam decreases, and by reducing the living cross-section in the interbarbel space, the distribution of the flow velocity will be more uniform, as a result, the values of corrections $\alpha$ and $\alpha 0$ decrease.

\section{Conclusions}

The obtained dependences (6), (7), (9), and (10) allow us to calculate $\alpha$ and $\alpha^{0}$ with oneway and two-way flow restrictions, taking into account the development between the dam space. They are valid in the presence of the initial part of the jet in the area of spreading.

\section{References}

1. Abramovich G.N. Theory of Turbulent Jets, p. 716, Moscow 1960 
2. Avrorova T.F. Hydraulic calculation of the river flow, constrained by a jumper, № 18 . L., (1969)

3. Altunin S.T. Canals Regulation. p. 336, (1956)

4. Bakiev M.R. Patterns of flow spreading behind the blind and through spur, p. 27. Tashkent, (1974)

5. Proceedings of the Department of Hydraulics of the Saratov Polytechnic Institute, №. 24, pp. 222-226, (1965)

6. Lebedev I.V. The main provisions of the hydraulic calculation of the construction layout of waterworks. 33, pp. 82, (1960)

7. Lvovskiy E.K. Statistical methods for constructing empirical formulas. - M.: Higher school, pp. 238, (1988)

8. Mikhalev M.A. Hydraulic flow calculation with whirlpool, L, Energy, pp. 184, (1971)

9. Rakhmonov A.N. On the influence of channel roughness on the length of the whirlpool of the expanding calm flow. News All-Russian Research Institute of Hydraulic Engineering, 83, pp. 58 - 103, (1967)

10. Soloveva A.G. Experimental study of the planned expansion of the flow in the presence of whirlpool zones. News All-Russian Research Institute of Hydraulic Engineering, volume. 46, pp. 33 - 52, (1951)

11. K. Khasanov, "Evaluation of ASTER DEM and SRTM DEM data for determining the area and volume of the water reservoir," IOP Conf. Ser. Mater. Sci. Eng., 883(1) (2020)

12. Huang W. Mathematical simulation of planar 2-D flow with submerged spur-dike. Sichuan Daxue Xuebao (Gongcheng Kexue Ban), Journal of Sichuan University (Engineering Science Edition) 37(1) pp. 19-23, (2005)

13. Bakiev M. Field target dimensions of flow constrained by a transverse dam. IOP Conference Series: Materials Science and Engineering. 883(1) (2020)

14. Maalem N., Khasanov Kh., Nishanbaev Kh. Morphometric elements of the channel and hydraulic flow parameters in the zone of the river backwater. IOP Conference Series: Materials Science and Engineering, 883(1), 012013 (2020)

15. M Bakiev et al. Regulation of the corse of the Aknangaran river. Gidrotekhnicheskoe Stroitel'stvo. 5, pp. 28-30, (1992)

16. Soliman M. Spur dike effects on the river Nile morphology after High Aswan Dam. Proceedings, Congress of the International Association of Hydraulic Research, IAHR A, pp. 805-810 (1997)

17. Muneta N. Numerical analysis model with spur-dike considering the vertical flow velocity distribution. Doboku Gakkai Rombun-Hokokushu/Proceedings of the Japan Society of Civil Engineers, 497, pp. 31-39, (1994)

18. M Bakiev et al. Safety of hydraulic structures, p. 110, Tashkent (2008)

19. Rakhmatullaev, S. Sedimentation of reservoirs in Uzbekistan: A case study of the Akdarya reservoir, Zerafshan River Basin, AHS-AISH Publication, 349, pp. 171-181 (2011)

20. Bazarov D., Markova I., Norkulov B. and Vokhidov O. Hydraulic aspects of the layout of head structures during water intake from lowland rivers. IOP Conf. Ser. Mater. Sci. Eng. 1015, 012041 (2021).

21. Bakiev M. and Khasanov K., "Comparison of Digital Elevation Models for Determining the Area and Volume of the Water Reservoir," Int. J. Geoinformatics, 17(1) pp. 37-45, (2021) 
22. Bazarov D., Vatin N., Obidov B., and Vokhidov O. Hydrodynamic effects of the flow on the slab of the stand in the presence of cavitation. IOP Conf. Ser. Mater. Sci. Eng. 1030, 012110 (2021).

23. Matyakubov B., Begmatov I., Raimova I. and Teplova G. Factors for the efficient use of water distribution facilities. IOP Conf. Ser. Mater. Sci. Eng. 883, 012025 (2020).

24. Krutov A., Choriev R., Norkulov B., Mavlyanova D. and Shomurodov A. Mathematical modelling of bottom deformations in the kinematic wave approximation. IOP Conf. Ser. Mater. Sci. Eng. 1030, 012147 (2021).

25. Uralov B., Rakhmatov N., Khidirov S., Uljaev F., Raimova I. Hydraulic modes of damless water intake. IOP Conf. Ser. Mater. Sci. Eng. 1030(1), 012123 (2021)

26. Krutov A., Norkulov B., Uljaev F., and Jamalov F. Results of a numerical study of currents in the vicinity of a damless water intake. IOP Conf. Ser. Mater. Sci. Eng. 1030, 012121 (2021).

27. Bazarov D., Markova I., Sultanov S. and Kattakulov F. Dynamics of the hydraulic and alluvial regime of the lower reaches of the Amudarya after the commissioning of the Takhiatash and Tuyamuyun hydrosystems. IOP Conf. Ser. Mater. Sci. Eng. 1030, 012110 (2021).

28. Bazarov D., Markova I., Raimova I., Sultanov Sh. Water flow motion in the vehicle of main channels. IOP Conf. Ser. Mater. Sci. Eng. 883, 012025 (2020).

29. Shokirov B., Norkulov B., Nishanbaev Kh., Khurazbaev M., Nazarov B. Computer simulation of channel processes. E3S Web of Conferences, 97, 05012, (2019)

30. Bazarov D. and Vokhidov O. Extinguishing Excess Flow Energy in Spillway Structures. In book: Proceedings of EECE 2020, LNCE 150, pp. 535-545, (2021) DOI: 10.1007/978-3-030-72404-7_52

31. Shomayramov, M., Norkulov B., Rakhmanov J., Tadjiyeva D., Suyunov J. Experimental researches of hydraulic vacuum breakdown devices of siphon outlets of pumping stations. E3S Web of Conferences, 97, 05009, (2019)

32. Obidov B., Vokhidov O., Tadjieva D., Kurbanova, U., Isakov A. Hydrodynamic effects on the flow elements of the downstream devices in the presence of cavitation. IOP Conf. Ser. Mater. Sci. Eng. 1030, 012114 (2021).

33. Bazarov D., Norkulov B., Vokhidov O., Uljaev F., Ishankulov, Z. Two-dimensional flow movement in the area of protective regulatory structures. IOP Conf. Ser. Mater. Sci. Eng. 890, 012162 (2020)

34. Krutov A., Norkulov B., Artikbekova F., Nurmatov P. Optimal location of an intake at a reservoir prone to salt diffusion. IOP Conf. Ser. Mater. Sci. Eng. 869(7), 072020, (2020)

35. Krutov A., Norkulov B., Mavlyanova D. Simulation of spreading of non-conservative passive substances in water bodies. IOP Conf. Ser. Mater. Sci. Eng. 883(1), 012028 (2020) 